\title{
Nonmotor Symptoms of Parkinson's Disease Revealed in an Animal Model with Reduced Monoamine Storage Capacity
}

\author{
Tonya N. Taylor, ${ }^{1,2}$ W. Michael Caudle, ${ }^{7}$ Kennie R. Shepherd, ${ }^{1,2}$ AliReza Noorian, ${ }^{1,3}$ Chad R. Jackson, ${ }^{4}$ \\ P. Michael Iuvone, ${ }^{4,5}$ David Weinshenker, ${ }^{6}$ James G. Greene, ${ }^{1,3,4}$ and Gary W. Miller ${ }^{1,2,3,4}$ \\ ${ }^{1}$ Center for Neurodegenerative Disease and ${ }^{2}$ Department of Environmental and Occupational Health, Rollins School of Public Health, and Departments of \\ ${ }^{3}$ Neurology, ${ }^{4}$ Pharmacology, ${ }^{5}$ Ophthalmology, and ${ }^{6}$ Human Genetics, School of Medicine, Emory University, Atlanta, Georgia 30322, and ${ }^{7}$ Department of \\ Pathology, University of Washington, Seattle, Washington 98104
}

Parkinson's disease (PD) is a progressive neurodegenerative disorder that is characterized by the loss of dopamine neurons in the substantia nigra pars compacta, culminating in severe motor symptoms, including resting tremor, rigidity, bradykinesia, and postural instability. In addition to motor deficits, there are a variety of nonmotor symptoms associated with PD. These symptoms generally precede the onset of motor symptoms, sometimes by years, and include anosmia, problems with gastrointestinal motility, sleep disturbances, sympathetic denervation, anxiety, and depression. Previously, we have shown that mice with a $95 \%$ genetic reduction in vesicular monoamine transporter expression (VMAT2-deficient, VMAT2 LO) display progressive loss of striatal dopamine, L-DOPA-responsive motor deficits, $\alpha$-synuclein accumulation, and nigral dopaminergic cell loss. We hypothesized that since these animals exhibit deficits in other monoamine systems (norepinephrine and serotonin), which are known to regulate some of these behaviors, the VMAT2-deficient mice may display some of the nonmotor symptoms associated with PD. Here we report that the VMAT2-deficient mice demonstrate progressive deficits in olfactory discrimination, delayed gastric emptying, altered sleep latency, anxiety-like behavior, and agedependent depressive behavior. These results suggest that the VMAT2-deficient mice may be a useful model of the nonmotor symptoms of PD. Furthermore, monoamine dysfunction may contribute to many of the nonmotor symptoms of PD, and interventions aimed at restoring monoamine function may be beneficial in treating the disease.

\section{Introduction}

Parkinson's disease (PD) is a neurodegenerative disease that has long been considered to be a disorder of the dopamine (DA) system. Pathophysiologically, PD is believed to be caused by the death of neuromelanin-containing DA neurons in the substantia nigra pars compacta ( $\mathrm{SNpc}$ ) and the appearance of proteinaceous intracellular inclusions known as Lewy bodies (Olanow and Tatton, 1999; Jenner and Olanow, 2006). Motor disturbances do not present clinically until $\sim 70-80 \%$ of striatal dopamine has already been lost; however, other nonmotor symptoms are evident before the onset of motor disturbances. These include hyposmia/ anosmia, gastrointestinal (GI) disturbances, sleep abnormalities, autonomic dysfunction, anxiety, depression, and, at later stages, impaired cognition (Braak et al., 2003; Langston, 2006). Moreover, a careful reading of James Parkinson's description of his patients indicates that many of the nonmotor symptoms that are

Received March 26, 2009; revised May 9, 2009; accepted May 21, 2009.

This work was supported by National Institutes of Health Grants P01 ES016731 (G.W.M.), 1F31ES017247-01 (T.N.T.), T32 ES007032 (W.M.C.), R01 EY004864 (P.M.I.), and T32 GM007092 (C.R.J.), National Science Foundation Grant 0450303 (C.R.J.), and the Michael J. Fox Foundation (J.G.G.). We thank Heather Mitchell and Dr. Jesse Schank for assistance with behavioral testing, Dr. Min Wang for assistance with the mouse colony, and Dr. Nikita Pozdeyev for technical assistance with ERG recordings. We are indebted to Dr. Piers Emson for providing the original VMAT2 hypomorph mouse strain.

Correspondence should be addressed to Gary W. Miller, Center for Neurodegenerative Disease, Emory University, Whitehead Biomedical Research Building, Room 505K, Atlanta, GA 30322. E-mail: gary.miller@emory.edu DOI:10.1523/JNEUROSCI.1495-09.2009

Copyright $\odot 2009$ Society for Neuroscience $\quad 0270-6474 / 09 / 298103-11 \$ 15.00 / 0$ of great interest today were observed nearly 200 years ago (Parkinson, 1817). It is possible that other neurotransmitters such as norepinephrine (NE) and serotonin (5-HT) may significantly contribute to these symptoms, as the locus ceruleus (LC) and raphe nucleus have also been shown to degenerate in PD (Dauer and Przedborski, 2003; Fahn and Sulzer, 2004; Rommelfanger and Weinshenker, 2007). This is supported by studies that show neurodegeneration in the LC, the primary source of NE, in addition to the SNpc, and evidence that perturbation of the noradrenergic system can lead to serious alteration in DA neurotransmission (Antelman and Caggiula, 1977; Gesi et al., 2000; Marien et al., 2004; Rommelfanger and Weinshenker, 2007). In contrast to DA and NE, 5-HT has been virtually absent from PD research, even though the raphe nuclei has been shown to undergo degeneration in PD patients (Braak et al., 2002, 2003). Although the degeneration of the raphe is not as prominent as that of the SNpc or LC, 5-HT is widely recognized in the development of many other diseases such as depression, psychiatric, and sleep disorders, all of which have been observed in PD patients (Halliday et al., 1990; Jellinger, 1991; Murai et al., 2001).

Recently, we have characterized a new potential model of PD based on reduced vesicular storage of monoamines. Animals expressing $5 \%$ of normal vesicular monoamine transporter 2 (VMAT2-deficient) exhibit increased oxidative stress, progressive loss of DA terminals and cell bodies in the SNpc, as well as $\alpha$-synuclein accumulation (Caudle et al., 2007). Monoaminergic dysfunction in the VMAT2-deficient animals arises from reduced 
expression of VMAT2, resulting in severely diminished levels of DA, NE, and 5-HT (Mooslehner et al., 2001; Caudle et al., 2007). Because VMAT2-deficient mice demonstrate a significant reduction in NE and 5-HT levels in multiple brain regions, our laboratory has characterized the behavioral manifestations of reduced monoaminergic innervation in the VMAT2-deficient mice. In this study, we report that the VMAT2-deficient mice display many of the nonmotor symptoms of PD.

\section{Materials and Methods}

Animals. Male and female VMAT2-deficient mice were generated as previously described (Mooslehner et al., 2001; Caudle et al., 2007). Briefly, the mouse VMAT2 locus (SLC18A2) was cloned from the $129 / \mathrm{Sv}$ genomic library and a $2.2 \mathrm{~kb} P v u I I$ fragment from the third intron of the VMAT2 gene, and cloned into the blunt-ended NotI site of the construct. The targeting vector was introduced into 129/Ola CGR 8.8 embryonic stem cells and injected into blastocytes of C57BL/6 mice. Highly chimeric males were bred with C57BL/6 females; genotype was confirmed by Southern blot analysis. A recent report uncovered that the C57BL/6 inbred strain of mice originally used to establish the VMAT2-deficient mouse line contained a spontaneous chromosomal deletion spanning the $\alpha$-synuclein gene locus (Specht and Schoepfer, 2001), which was confirmed in the original strain (Mooslehner et al., 2001; Patel et al., 2003; Colebrooke et al., 2006). Through diligent breeding, we eliminated all traces of this mutation from our strain of mice and routinely verified the presence of $\alpha$-synuclein via Southern blot analysis. This report represents the second set of data on VMAT2-deficient mice with a normal $\alpha$-synuclein background. All mice were generated through redundant breeding of mice that were heterozygous for the VMAT2 allele and wild type (WT) for the $\alpha$-synuclein allele. The genotype of all mice was confirmed by PCR of DNA extracted from tail samples. For all behavioral tests, VMAT2 WT littermate controls were used. All procedures were conducted in accordance with the National Institutes of Health Guide for Care and Use of Laboratory Animals and previously approved by the Institutional Animal Care and Use Committee at Emory University.

HPLC determination of monoamines and metabolites. HPLCelectrochemical analysis of neurochemistry was performed as previously described (Richardson and Miller, 2004; Caudle et al., 2006, 2007). Briefly, dissected right striata, cortex, and hippocampus were sonicated in $0.1 \mathrm{M}$ perchloric acid containing $347 \mu \mathrm{M}$ sodium bisulfate and $134 \mu \mathrm{M}$ EDTA. Homogenates were centrifuged at $10,000 \times g$ for $10 \mathrm{~min}$ at $4^{\circ} \mathrm{C}$; the supernatant was removed and filtered through a $0.22 \mu \mathrm{m}$ filter by centrifugation at $5000 \times g$ for $3 \mathrm{~min}$. The supernatants were then analyzed for levels of DA, DOPAC, homovanillic acid, NE, 5-HT, and 5-HIAA. Levels were measured using HPLC with an eight-channel coulometric electrode array (ESA Coularray; ESA Laboratories). Quantification was made by reference to calibration curves made with individual standards.

Olfactory discrimination. Olfactory experiments were adapted from previous work from our laboratory (Tillerson et al., 2006). Briefly, wooden blocks $\left(1.8 \mathrm{~cm}^{3}\right)$ were placed individually in $50 \mathrm{ml}$ conical tubes containing $1 \mathrm{~g}$ of animal bedding from test animals' cages for $12 \mathrm{~h}$. The animal was presented with a block scented with its own bedding and a block scented with another mouse's bedding (of the same sex). The time spent sniffing (nose $<1 \mathrm{~cm}$ away from the block) or in contact with each block was recorded for a 2 min trial (Tillerson et al., 2006). A single cohort of mice was tested at each time point; however, naive mice were introduced each month to ensure that the original cohort of mice was not learning the task. Data from male and female mice were combined, since there were no detectable sex differences after testing 20 mice per genotype.

To measure nonsocial olfactory acuity, methods were modified from previous methods used in our laboratory (Tillerson et al., 2006). Glass plates with $25 \mu \mathrm{l}$ of either a novel scent (lemon, peppermint, or vanilla) or water were presented simultaneously to the animals. Time spent sniffing each glass plate was recorded for a 3 min session.

Non-olfactory sensory tests. To assess nonolfactory sensory function in VMAT2 WT and deficient mice, we examined the responses of these
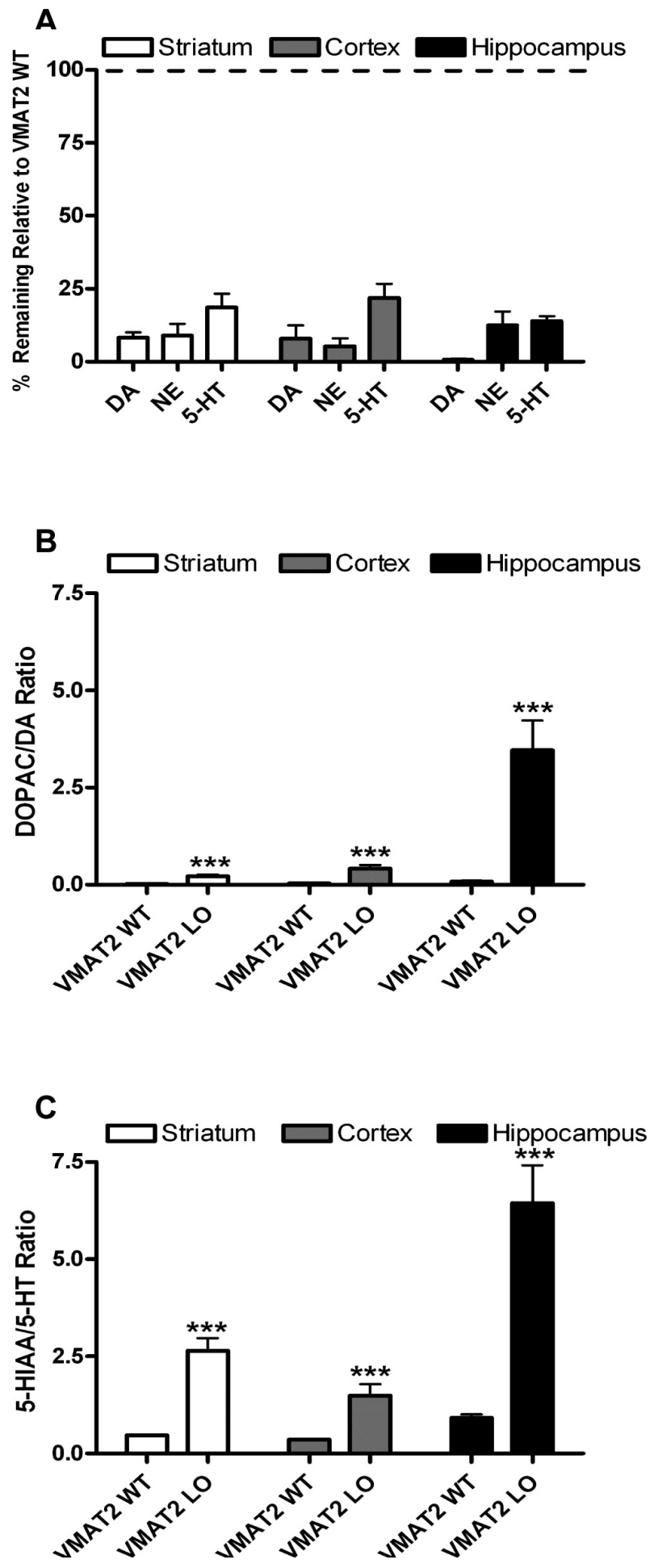

Figure 1. VMAT2 LO mice display widespread reductions in monoamines at 12-15 months of age. $\boldsymbol{A}$, All monoamine levels are significantly lower than age-matched wild-type controls at 12-15 months of age in the striatum, cortex, and hippocampus. Results represent the mean ratios of raw values ( $\mathrm{ng} / \mathrm{mg}$ tissue) \pm SEM for eight animals per genotype. $\boldsymbol{B}, \boldsymbol{C}$, Ratio of DOPAC/DA and 5-HIAA/5-HT in the striatum, cortex, and hippocampus of VMAT2 WT and VMAT2 LO mice. Results represent the mean ratios of raw values ( $\mathrm{ng} / \mathrm{mg}$ tissue) $\pm \mathrm{SEM}$ for four animals per genotype. ${ }^{* * *} p<0.001$.

animals in several sensory tests using the paradigm of Tillerson et al. (2006). Responsiveness to tactile stimulation was measured as latency to contact or remove a $113.1 \mathrm{~mm}^{2}(1.3 \mathrm{~cm}$ in diameter $)$ adhesive dot in a 2 min session (Avery Office International) (Schallert et al., 2000; Tillerson 


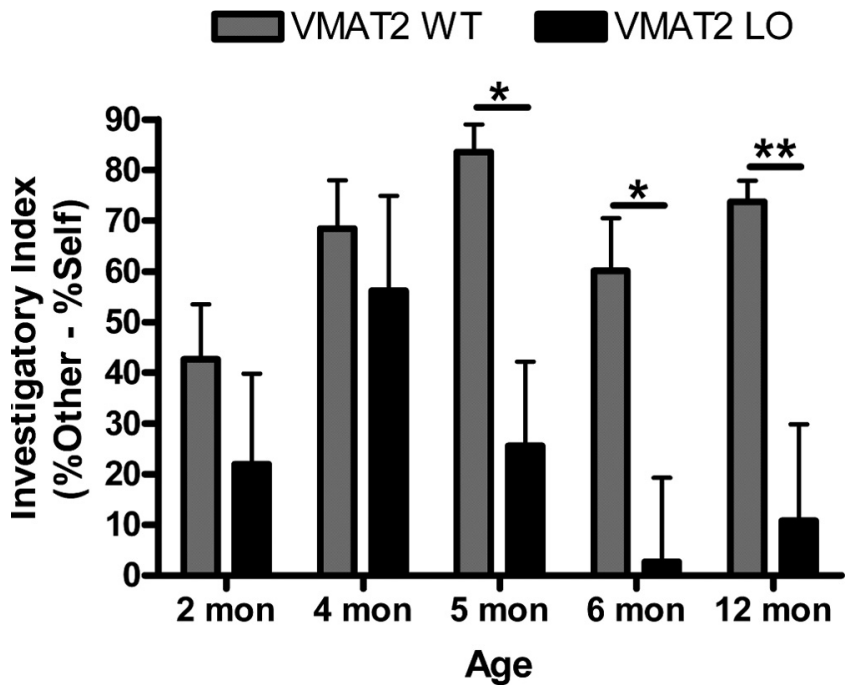

Figure 2. VMAT2 $\mathrm{L} 0$ animals display progressive deficits in olfactory discrimination. When given the choice between a wooden block scented with a foreign animal's bedding and a block scented with the animal's own bedding, VMAT2 WT animals show preferential exploration of the block scented with the foreign animal's bedding at all ages, as shown by the investigatory index. The investigatory index represents the percentage of time the animal spent sniffing the block scented with a foreign animal's bedding minus the percentage of time the animals spent sniffing the block scented with their own bedding. Conversely, VMAT2 L0 animals exhibit a preferential exploration at 2 and 4 months of age, with a significant decrease at 5 months of age, worsening at 6 and 12 months of age. Results represent the investigatory index \pm SEM for $10-15$ animals per genotype. ${ }^{*} p<0.05 ;{ }^{* *} p<0.01 ;{ }^{* * *} p<0.001$.

et al., 2006). Animals were removed from their home cage, and the dot placed between the ears, on top of the head. Animals were then put back into their home cage and the cage returned to its normal position on the rack to reduce external distractions (Tillerson et al., 2006).

Quinine is often used in taste aversion paradigms, due to its unpalatable bitterness (Tillerson et al., 2006). The tip of a cotton swab was placed into either an aliquot of $2 \mathrm{mg} / \mathrm{ml}$ quinine or water and then into the animals' mouths. Presentation of clean versus quinine stimuli was counterbalanced between animals. Latency to groom and/or drag the jaw along the ground was recorded during a 1 min test session (Grill and Norgren, 1978; Schallert and Whishaw, 1978; Tillerson et al., 2006).

The trigeminal nerve innervates areas of the olfactory epithelium and nasal mucosa, and is responsible for nonodor sensations such as mild irritation and burning (Tillerson et al., 2006). In this test, we assessed the function of the trigeminal nerve by exposing the mice to either ammonia, known to exert a trigeminal response, or water. A glass plate with water or ammonia (counterbalanced between animals) was placed in the animal's cage. Time sniffing (as defined above) was recorded for a 2 min session (Tillerson et al., 2006).

Sleep latency. VMAT2 WT and deficient animals were individually housed in large Plexiglas cages and allowed to acclimate for $4 \mathrm{~h}$. Saline $(0.9 \%)$ was then administered intraperitoneally and mice were observed by a trained experimenter for behavioral signs of sleep. Sleep was defined as $2 \mathrm{~min}$ of uninterrupted sleep behavior, and $75 \%$ of the next $10 \mathrm{~min}$ spent asleep (Mitchell et al., 2008). A single cohort of mice was tested at all time points.

Gastric emptying. Following a $12 \mathrm{~h}$ fast, VMAT2 WT and deficient mice were allowed ad libitum access to food for $1 \mathrm{~h}$. The amount of food consumed was calculated based on food weight before and after access. Two hours after food removal, animals were killed and the stomach contents were weighed (wet and dry). The percentage of food remaining in the stomach was measured (Whited et al., 2006). Since this is a terminal procedure, separate cohorts of VMAT2 WT and deficient mice were aged and subjected to analysis for each time point.

One hour stool collection. Each mouse was placed in a separate clean cage and observed throughout the 60 min collection period. Fecal pellets were collected immediately after expulsion and placed in sealed (to avoid evaporation) $1.5 \mathrm{ml}$ tubes. Tubes were weighed to obtain the wet weight of the stool, this was then dried overnight at $65^{\circ} \mathrm{C}$ and reweighed to obtain the dry weight (Li et al., 2006).

Forced swim test. These studies were conducted on mice using a modified method of Porsolt et al. (1979). All mice were injected intraperitoneally with $100 \mu \mathrm{l}$ of $5 \mathrm{mg} / \mathrm{kg}$ desipramine (Sigma-Aldrich) or saline 30 $\mathrm{min}$ before testing. Mice were placed individually in glass cylinders $(24 \times$ $16 \mathrm{~cm}$ ) with $15 \mathrm{~cm}$ of water maintained at $25^{\circ} \mathrm{C}$. The mice were left in the cylinder and their behavior was videotaped from the side of the cylinder for $6 \mathrm{~min}$. After the first $2 \mathrm{~min}$, the total duration of time spent immobile was recorded during a $4 \mathrm{~min}$ test. The mouse was deemed immobile when it was floating passively; subtle movement of feet or tail required to keep the head above the surface of the water were excluded as immobility. Immobility time refers to the time that the animal spent floating for at least 3 s (Porsolt et al., 1979; Xu et al., 2000; Fukui et al., 2007). A single cohort of mice was tested at each time point; however, naive mice were introduced each month to ensure that the original cohort of mice was not learning the task.

Tail suspension test. These experiments were conducted using the methods of Cryan et al. (2004). All mice were injected intraperitoneally with $100 \mu \mathrm{l}$ of $5 \mathrm{mg} / \mathrm{kg}$ desipramine (Sigma-Aldrich) or saline $30 \mathrm{~min}$ before testing. Mice were individually suspended by the tail to a horizontal ring stand bar (distance from the floor $=30 \mathrm{~cm}$ ) using adhesive tape. A 6 min test session was videotaped and scored by a trained observer for escape-oriented behavior and bouts of immobility. The time spent immobile was recorded for each mouse. Mice were excluded from the study if they were able to climb on top of the ring stand. A single cohort of mice was tested at each time point; however, naive mice were introduced each month to ensure that the original cohort of mice was not learning the task.

Elevated plus maze. Male and female VMAT2 WT and deficient mice were individually housed in a reversed light cycle room (lights on at 7:00 P.M., lights off at 7:00 A.M.), and were allowed a minimum of 2 weeks to habituate to the new lighting conditions. Food and water were available ad libitum throughout the course of the study. Data from male and female mice were combined, since there were no detectable sex differences.

The elevated plus maze (EPM) paradigm was adapted from Schank et al. (2008). The EPM apparatus consisted of two open arms and two enclosed arms arranged in a plus-sign orientation. The arms were elevated 30 inches above the floor, with each arm projecting 12 inches from the center. Because rodents naturally prefer dark, enclosed compartments, a greater willingness to explore the open, well lit arms is believed to represent a decrease in the animal's anxiety (Pellow et al., 1985; File et al., 1988; Paine et al., 2002).

No drugs were administered before behavioral testing. To begin each test, mice were placed in the EPM, facing an open arm and allowed to freely explore the apparatus during a videotaped, $5 \mathrm{~min}$ trial. Videotapes were later scored by an observer who was blind to genotype. The measure used for analysis is the percentage of time spent exploring the open arms, which was calculated by dividing the time spent in the open arms by the combined time spent in open and closed arms (Pellow et al., 1985). Entry into an arm of the EPM was defined as the animal placing all four paws in that particular part of the maze. All tests were run during the dark cycle, between 2:00 and 4:00 P.M. Mice were excluded from data analysis if they jumped or fell off the maze after the test began.

Grid test. The grid test was performed using the methods of Tillerson and Miller (2003). Mice were placed horizontally on the center of the grid and supported until they grasped the grid with their forepaws and hindpaws. The grid was then inverted, and the mice were videotaped while hanging upside down for latency to release their grip on the grid.

Electroretinography. VMAT2 WT and deficient mice were dark adapted for at least $12 \mathrm{~h}$ and anesthetized with a ketamine $(60 \mathrm{mg} / \mathrm{kg})$ (Hospira)/xylazine $(7.5 \mathrm{mg} / \mathrm{kg}$ ) (Sigma-Aldrich) mixture for recording the scotopic flash electroretinography (ERG). Pupils were dilated with $1 \%$ cyclopentolate $1 \%$ tropicamide solutions. A DTL-fiber working electrode was placed on the cornea of the eye, while the reference needle electrode was placed on the cheek just below the eye. A ground electrode was attached to the tail of the mouse and a rectal probe was inserted to 

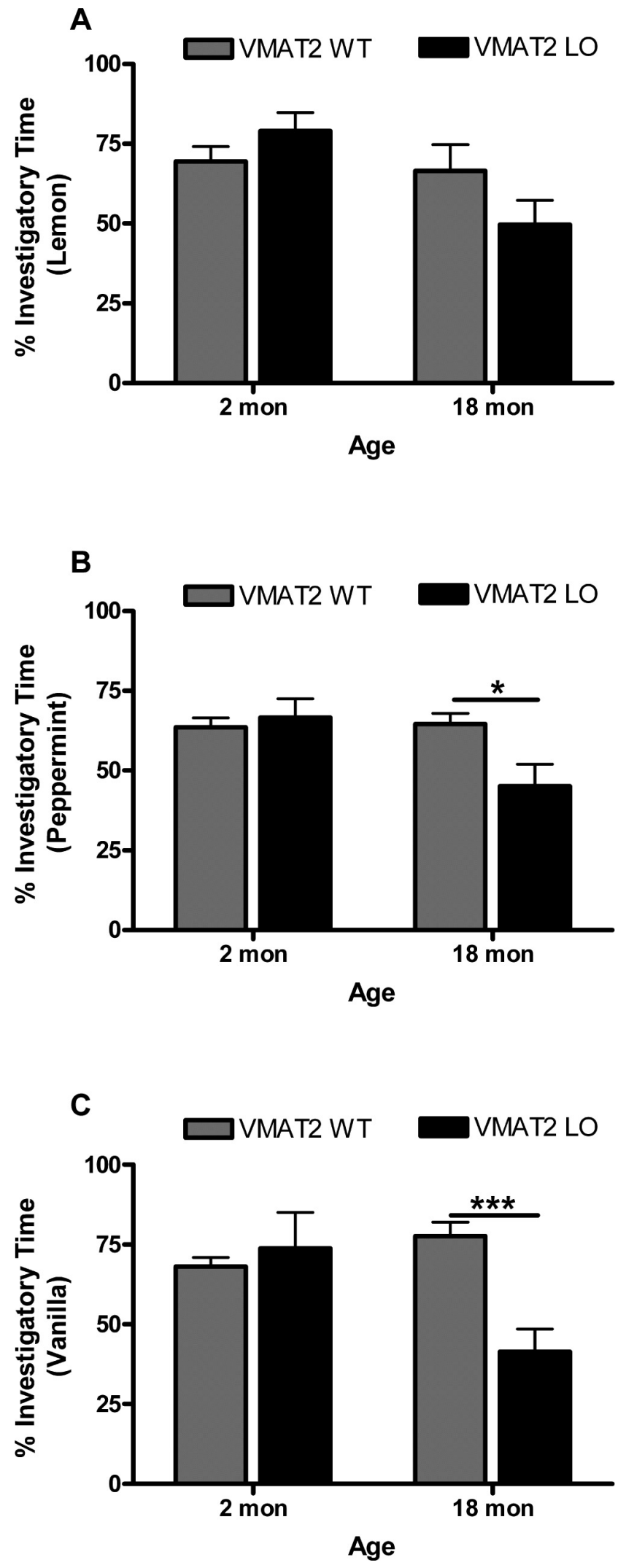

Figure 3. VMAT2 LO mice display age-dependent deficits in nonsocial olfactory acuity. $\boldsymbol{A}$, When given the choice between a novel odor (lemon) and water, both genotypes show a preferential exploration of the novel scent at 2 months of age, but the VMAT2 LO mice lose the ability to discriminate between lemon and water by 18 months of age. $B, C, V M A T 2 L O$ animals display similar behaviors at 18 months of age when presented with the novel odors of peppermint $(\boldsymbol{B})$ and vanilla $(\boldsymbol{C})$. Results represent the time spent investigating each scent \pm SEM for 10 animals per genotype. ${ }^{* *} p<0.01 ;{ }^{* * *} p<0.001$. monitor and control the temperature of the mouse. After recording a flat baseline, the mouse was exposed to multiple flashes of light with increasing intensities $(0.111,0.228,0.576,1.16,2.325,5.85$, and 119.6 $\left.\mathrm{cd} \cdot \mathrm{s} \cdot \mathrm{m}^{-2}\right)$. The responses to $3-10$ flashes at each intensity were averaged to determine a-wave amplitude, b-wave amplitude, a-wave implicit time, and b-wave implicit time.

Statistical analysis. Data from male and female mice was combined, since there were no detectable sex differences. All data were analyzed using unpaired independent-samples Student's $t$ test (gastric emptying), completely randomized two-factor ANOVA followed by Bonferroni post hoc analysis (odor discrimination, olfactory acuity, sleep latency, gastric emptying, forced swim test, tail suspension test), or repeated-measures two-factor ANOVA (ERGs). Analyses were completed using GraphPad Prism 5.0 for Windows, and for all tests all post hoc measures were error corrected to keep the overall error rate per group at 0.05 .

\section{Results}

VMAT2-deficient mice have diminished levels of monoamines at 12-15 months of age, accompanied by increased turnover

Previously, our laboratory has shown that VMAT2-deficient animals have age-dependent reductions in levels of striatal dopamine, accompanied by increased turnover (Caudle et al., 2007). To determine whether the reduction in VMAT2 affect the other major monoamines in addition to DA, the striatum, cortex, and hippocampus were isolated from VMAT2 WT and deficient mice and analyzed by HPLC for neurochemical levels. At 12-15 months of age, the VMAT2-deficient mice had severely diminished levels of all three monoamines in all brain regions tested, although in general, DA and NE depletion were more severe than 5-HT depletion. In the striatum, DA and NE were decreased by $91 \%$, while $5-\mathrm{HT}$ was decreased by $81 \%$. Similarly, in the cortex there was a $92 \%$ and $94 \%$ decrease in DA and NE, respectively, with only a 78\% decrease in 5-HT. However, in the hippocampus, a $99 \%$ decrease in DA was seen, while NE and 5-HT were decreased by $87 \%$ and $86 \%$, respectively (Fig. $1 A$ ). VMAT2deficient animals also had significantly increased DA and 5-HT turnover; a two-way ANOVA revealed a significant brain regionby-genotype interaction for both $\mathrm{DA}\left(F_{(2,38)}=80.91 ; p<0.0001\right)$ and 5-HT turnover $\left(F_{(2,44)}=26.09 ; p<0.0001\right)$ (Fig. $\left.1 B, C\right)$.

VMAT2-deficient mice display progressive olfactory discrimination deficits

One of the earliest manifestations of PD is the loss of the sense of smell. Olfactory abnormalities have been found in nearly all PD patients and can precede neurological deficits by decades (Braak et al., 2002, 2003; Langston, 2006). To determine whether VMAT2-deficient animals exhibit comparable olfactory dysfunction, both VMAT2 WT and deficient animals were subjected to a battery of olfactory discrimination tests. First, VMAT2 WT and deficient animals were subjected to odor discrimination tests, using wooden blocks scented with either home cage bedding or bedding from the cage of a foreign mouse of the same sex. No differences were seen between the behavior of VMAT2 WT or deficient animals at 2 and 4 months of age shown as the investigatory index (percentage of time spent investigating self - percentage of time spent investigating other; $n=12$ ) (Fig. 2). However, at 5, 6, and 12 months of age, VMAT2-deficient animals were unable to discriminate between the two blocks, and consequently displayed no preferential exploration of either block (2 months: percentage self $=28.19$, percentage other $=71.81 ; 12$ months: percentage self $=44.63$, percentage other $=55.37$; interaction between effects of scent and age: $F_{(4,95)}=2.41, p<0.05$, $n=12$ ) (Fig. 2). In contrast, VMAT2 WT mice show marked 

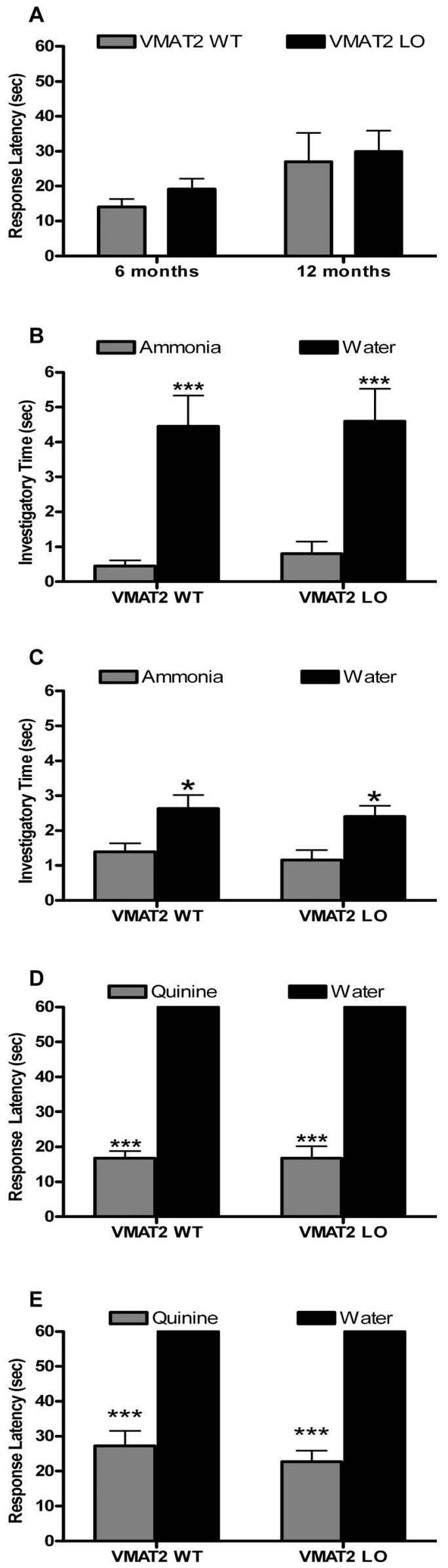

preferential exploration of the block scented with foreign bedding $\left(n=12-15\right.$, main effect of scent: $F_{(1,110)}=546.44, p<$ 0.0001 ), with no change in behavior as they aged (2 months: percentage self $=28.69$, percentage other $=71.31,12$ months: percentage self $=13.14$, percentage other $=86.86$; main effect of age: $\left.F_{(4,110)}=0.36, p=0.8379\right)$. To ensure that these results were not due to differences in motivation, the total investigatory time was calculated for both genotypes of mice at all ages. Investigatory times were similar at 4 months (WT: $5.36 \pm 0.6505, n=11$; LO: $\left.4.50 \pm 1.167, n=10 ; t_{(19)}=0.6627, p=0.5155\right), 5$ months (WT: $6.17 \pm 0.5618, n=12$; LO: $5.00 \pm 0.9309, n=10 ; t_{(20)}=$ $1.114, p=0.2785$ ), and 6 months of age (WT: $4.36 \pm 0.8232, n=$ 11; LO: $\left.2.80 \pm 0.4667, n=10 ; t_{(19)}=1.608, p=0.1244\right)$; only at 12 months of age did the VMAT2-deficient animals display a significant reduction in total investigatory time relative to agematched WT littermates (WT: $9.11 \pm 0.8219, n=15$; LO: $5.52 \pm$ $\left.1.418, n=11 ; t_{(24)}=2.325, p=0.0288\right)$. The olfactory deficit is not corrected by L-DOPA treatment in human PD patients, nor is it effective in our mice. Acute administration of L-DOPA and the peripheral aromatic acid decarboxylase inhibitor, benserazide, did not affect the performance of either genotype (data not shown) (Müller et al., 2002). Two-way ANOVA exposed a significant scent/genotype interaction; VMAT2-deficient mice also had deficits in nonsocial olfactory acuity using the scents of lemon (interaction between effects of genotype and age: $F_{(1,32)}=$ $3.69, p=0.0637$ ), vanilla (interaction between effects of genotype and age: $F_{(1,34)}=10.04, p=0.0032$ ), and peppermint (interaction between effects of genotype and age: $F_{(1,36)}=4.91, p=$ 0.0331 ), beginning at 3 months of age (data not shown) and persisting until 18 months of age (Fig. 3).

Mice were tested for nonolfactory sensory deficits to ensure that there was not a problem in general sensory perception. VMAT2-deficient animals showed no deficits in response to tactile stimulation (interaction between effects of genotype and age: $F_{(1,45)}=0.03, p=0.8679$ ), quinine-induced taste aversion (main effect of genotype: $F_{(1,44)}=0.00, p=0.9830$ ), or to mild irritation/burning sensations stimulated by ammonia (main effect of genotype: $\left.F_{(1,38)}=0.14, p=0.7136\right)$ compared with age matched WT controls (Fig. 4). Collectively, these results demonstrate that although the VMAT2-deficient animals have normal tactile and gustatory sensory perception, they do exhibit progressive deficits in olfactory discrimination, which is a common phenotype seen in PD.

VMAT2-deficient animals display altered latency to behavioral signs of sleep

Many PD patients experience sleep disturbances, including excessive sleepiness and insomnia (Comella, 2003; Langston, 2006; Ziemssen and Reichmann, 2007). To begin investigating behavioral sleep disturbances in the VMAT2-deficient mice, we conducted sleep latency tests in VMAT2 WT and deficient mice during their circadian nadir. Beginning at 2 months of age, VMAT2deficient mice show a shorter latency to behavioral signs of sleep, which is most prevalent at $4-6$ months of age, than age-matched

$\leftarrow$

Figure 4. VMAT2 LO mice do not display deficits in general sensory behavioral tests. A, At 6 months and 12 months of age VMAT2 L0 mice display similar response latencies to tactile stimulation in the dot test. $\boldsymbol{C}, \boldsymbol{D}$, Trigeminal nerve function in VMAT2 wild-type and $L 0$ animals was tested by response to ammonia. Like the VMAT2 WT mice, VMAT2 L0 mice displayed preferential exploration of water compared with ammonia at both $6(B)$ and $12(C)$ months of age. Gustatory function was also found to be normal in VMAT2 L0 mice at $6(\boldsymbol{D})$ and $12(\boldsymbol{E})$ months of age as measured by the quinine taste aversion test. 
WT controls (interaction effects of genotype and age: $F_{(4,73)}=$ 2.82, $p=0.0310)$. A Bonferroni post hoc analysis compared the two genotypes at each age; the difference in sleep latency between VMAT2-deficient and WT animals becomes increasingly less pronounced, and is absent at 24 months of age (Fig. 5A). While VMAT2 WT animals display an age-dependent decrease in sleep latency, no age-related changes in sleep latency occur in VMAT2deficient mice. The circadian activity of VMAT2-deficient animals is also significantly lower than that of age-matched WT controls at $4-6$ months of age (main effect of genotype: $F_{(1,156)}=$ $37.19, p<0.0001$ ), but not at 12-15 (main effect of genotype: $F_{(1,228)}=2.62, p=0.1072$ ) or 18 months of age (main effect of genotype: $\left.F_{(1,168)}=1.16, p=0.2827\right)$, due to a decline in WT circadian activity at the latter ages (Fig. $5 B-E$ ). These results suggest that VMAT2-deficient mice develop premature changes in sleep latency and are displaying behavioral phenotypes reminiscent of older WT animals.

\section{VMAT2-deficient mice have delayed gastric emptying}

Gastrointestinal dysfunction in PD occurs in $>70 \%$ of PD patients and has been attributed to lack of activity, inadequate hydration, or autonomic and enteric neuronal dysfunction (Langston, 2006; Ziemssen and Reichmann, 2007). To study this nonmotor symptom in VMAT2-deficient mice, WT and deficient animals were behaviorally examined for gastric emptying at $2,6,12$, and 18 months of age. Student's $t$ test revealed that solid gastric emptying was significantly delayed overall in VMAT2deficient mice (WT: $21.98 \pm 2.605 n=16, \mathrm{LO}: 30.27 \pm 2.101 n=$ $\left.16, t_{(28)}=2.478, p=0.0195\right)$, and was most apparent at 2, 6, and 12 months of age, although not significant as shown by two-way ANOVA with Bonferroni post hoc analysis $(n=16$ per genotype, interaction effects of age and genotype: $F_{(3,21)}=0.63, p=0.6043$ ) (Fig. 6A). Two-way ANOVA revealed stool frequency to be altered in VMAT2-deficient mice, with a significant increase in frequency at 2 and 6 months of age, compared with VMAT2 WT animals $(n=4$ per genotype, interaction effects of age and genotype: $\left.F_{(3,24)}=8.79, p=0.0004\right)($ Fig. $6 B)$.

\section{VMAT2-deficient mice display anxiety-like and depressive phenotypes}

One of the most prevalent nonmotor symptoms of PD is depression, with signs of anxiety comorbid in patients with major depression (Zimmerman et al., 2002; Fukui et al., 2007). Anxietylike behavior was measured in VMAT2 WT and deficient animals using the elevated plus maze. Younger VMAT2-deficient mice (4-6 months) spent significantly more time in the closed arms of the maze compared with age-matched controls ( $n=11-12$, interaction effects of age and genotype: $\left.F_{(1,38)}=3.45, p<0.05\right)$ (Fig. 7A), while older VMAT2-deficient mice (12-15 months) did not display an anxiety-like phenotype compared with agematched WT controls. Similar to what we observed in the sleep latency test, the behavior of VMAT2 WT animals in this test changed over time, while that of VMAT2-deficient mice did not, indicating possible premature development of symptoms normally associated with older animals.

The VMAT2-deficient animals were tested for altered behavior in the forced swim (FST) and tail suspension (TST) tests. At 4-6 months of age, there was no difference found between the immobility times of VMAT2 WT and deficient animals in both tests, and neither genotype responded to an acute low dose of desipramine $(5 \mathrm{mg} / \mathrm{kg}$ administered $20 \mathrm{~min}$ before testing) $[n=$ $4-6$, interaction effects of drug treatment and genotype: $F_{(1,13)}=$ $0.53, p=0.4807$ (FST); $F_{(1,13)}=0.08, p=0.7827$ (TST)] (Fig.
$7 B, C)$. However, at $12-15$ months of age, immobility times were higher in VMAT2-deficient animals compared with age-matched WT controls $\left[n=4-5\right.$, main effect of genotype: $F_{(1,15)}=9.72$, $\left.p=0.0071(\mathrm{FST}) ; F_{(1,16)}=11.12, p=0.0042(\mathrm{TST})\right]($ Fig. $7 D, E)$. The differences in immobility times across age groups in VMAT2-deficient animals suggests that there is an agedependent development of depressive behavior, which correlates with the progressive neurochemical deficits previously characterized (Mooslehner et al., 2001; Caudle et al., 2007). Initially, both VMAT2 WT and deficient mice were exposed to $20 \mathrm{mg} / \mathrm{kg}$ desipramine, which was found to decrease immobility times in both genotypes (data not shown). However, when treated with an acute low dose of desipramine $(5 \mathrm{mg} / \mathrm{kg}$ administered i.p. $20 \mathrm{~min}$ before testing), the immobility times of VMAT2-deficient mice decreased to WT levels $[n=4-5$, interaction effects of treatment and genotype: $F_{(1,15)}=5.55, p=0.0325(\mathrm{FST}) ; F_{(1,16)}=7.95, p=$ 0.0123 (TST)] (Fig. $7 D, E$ ); the immobility times of VMAT2 WT animals were not affected by desipramine at $12-15$ months of age.

\section{VMAT2-deficient mice display normal vision and muscle strength}

While the phenotypic behaviors help define the disease, the lack of deficits in other systems are also important in showing the relative selectivity. As in $\mathrm{PD}$, other sensory systems appear to be functioning normally in the VMAT2-deficient mice (Figs. 3, 4); moreover, vision and muscle strength have also been found to be normal in patients. Although VMAT2-deficient mice had significantly decreased DA (64\%) and DOPAC (45\%) (interaction effects of neurotransmitter and genotype: $F_{(1,20)}=16.28, p=$ 0.0006 ) (Fig. $8 A$ ), the magnitude of the decrease was substantially less than that found in the brain regions examined and was coupled with increased DA turnover (WT: $0.2434 \pm 0.039 n=6$, LO: $\left.0.4017 \pm 0.056 n=6, t_{(10)}=2.317, p=0.0430\right)$. Consequently, visual function appeared to be normal. Visual function was quantified by use of ERG. The ERG can detect abnormalities in electrical responses of the photoreceptor cells (rods and cones) and inner retinal cells (bipolar, amacrine, and ganglion cells). Compared with wild-type littermates, VMAT2-deficient mice displayed no differences in A-wave amplitude (main effect of genotype: $F_{(1,4)}=0.04, p=0.8569$ ) or implicit time (main effect of genotype: $F_{(1,4)}=0.04, p=0.8480$ ) or B-wave amplitude (main effect of genotype: $F_{(1,4)}=0.28, p=0.6237$ ) or implicit time (main effect of genotype: $F_{(1,4)}=0.02, p=0.8895$ ) when their retinas were stimulated with light flashes as revealed by repeatedmeasures two-way ANOVA with Bonferroni post hoc analyses (Fig. $8 B-E$ ). In addition, $A d c y 1$ mRNA expression, which is regulated in retina by $\mathrm{DA} \mathrm{D}_{4}$ receptors (Jackson et al., 2009), was not different between VMAT2-deficient $(2.450 \pm 0.4204, n=11)$ and wild-type mice $\left(2.112 \pm 0.4775, n=10 ; t_{(10)}=0.5324, p=\right.$ $0.8019)$. General muscle strength was assessed by subjecting VMAT2 WT and deficient animals to the grid test. VMAT2deficient mice showed no difference in latency to fall on the grid test apparatus compared with age-matched WT animals (data not shown).

\section{Discussion}

Although PD has been traditionally viewed as a neurodegenerative motor disorder, the increasing recognition of nonmotor symptoms, including hyposmia, sleep abnormalities, anxiety, depression, and gastric dysfunction, suggests the disease is more multifaceted than commonly thought. Moreover, these symptoms imply that more general monoaminergic dysfunction is occurring in concert with DA degeneration. Evidence for degener- 

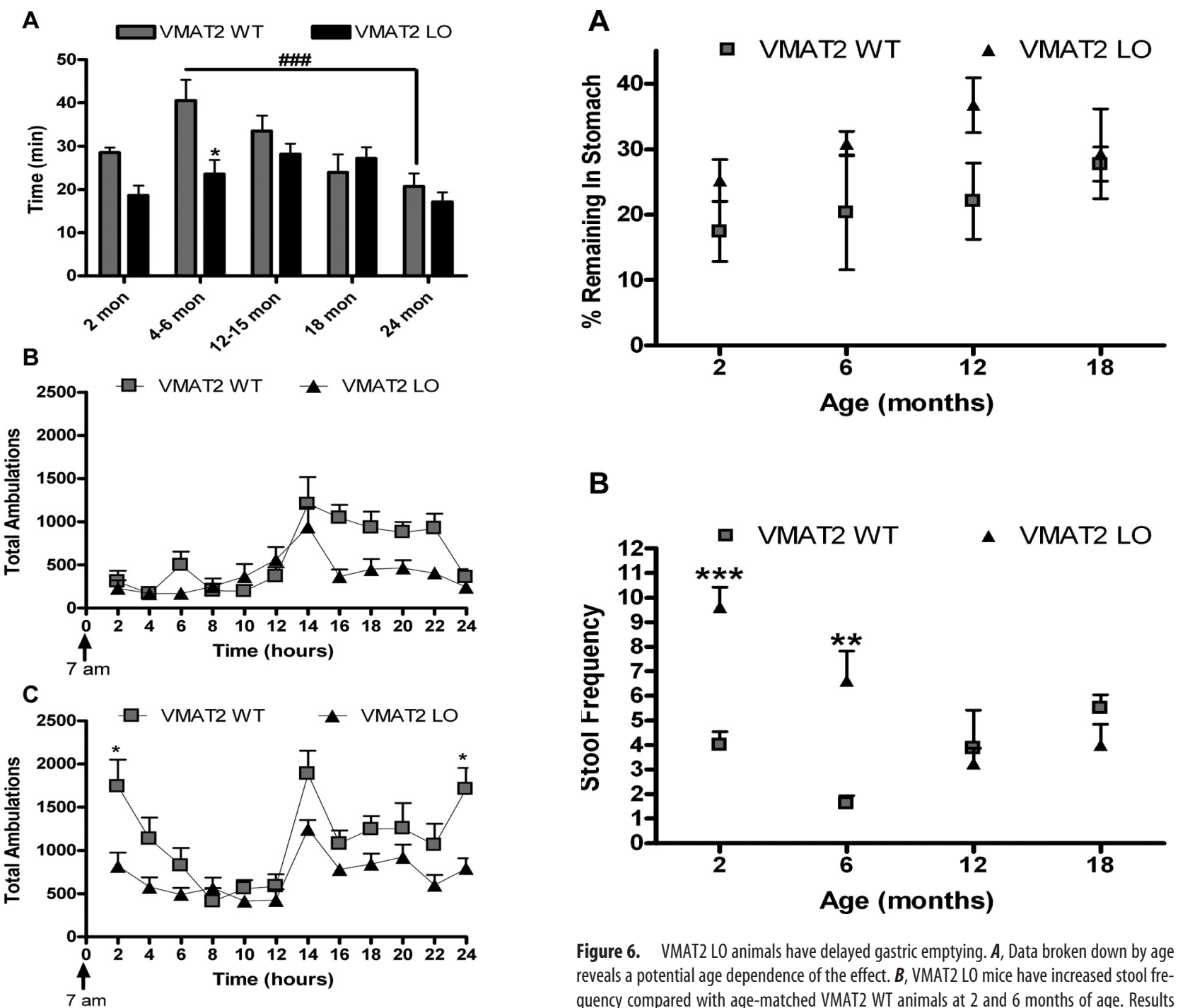

Figure 6. VMAT2 $L 0$ animals have delayed gastric emptying. $A$, Data broken down by age reveals a potential age dependence of the effect. $\boldsymbol{B}$, VMAT2 $L 0$ mice have increased stool frequency compared with age-matched VMAT2 WT animals at 2 and 6 months of age. Results represent average stool frequency for two trials \pm SEM for four animals per genotype. ${ }^{* *} p<$ $0.01 ;{ }^{* * *} p<0.001$.
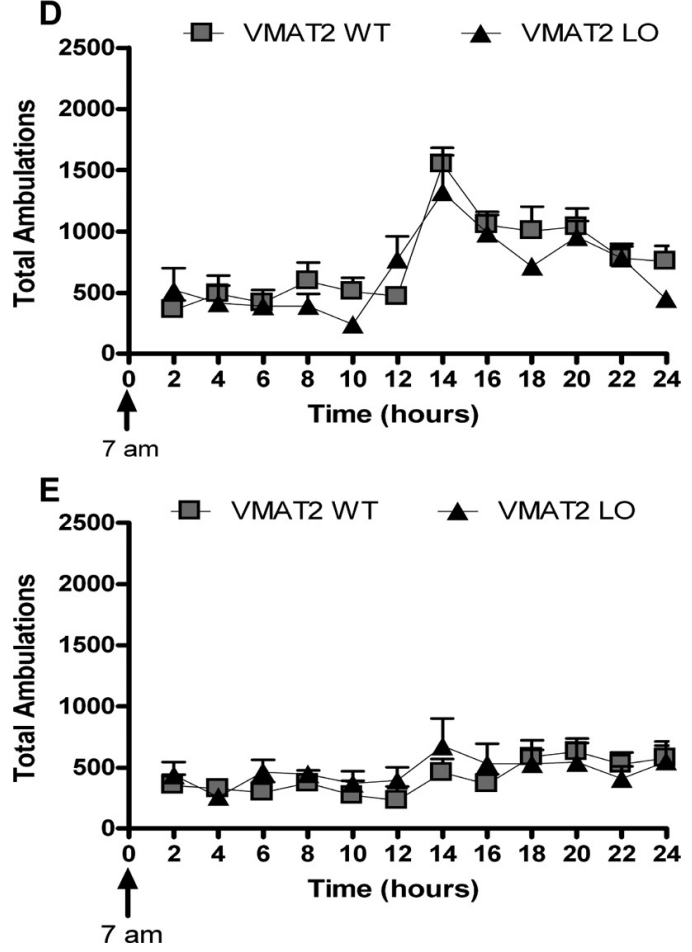

ation of the LC and dorsal raphe (DR) in PD patients highlights the importance of looking beyond the nigrostriatal system to illuminate the deficits in other neurotransmitter systems (Braak et al., 2002, 2003; Dauer and Przedborski, 2003; Fahn and Sulzer, 2004; Lemke et al., 2004; Rommelfanger and Weinshenker, 2007). In this study, we hypothesized that general monoamine dysfunction may recapitulate many of the nonmotor symptoms of PD. We observed a reduction in monoamines that was associated with behavioral dysfunction.

Previous neurochemical analysis of VMAT2-deficient animals shows general age-dependent reductions in brain tissue levels of DA, NE, epinephrine, and 5-HT by 80-90\% (Mooslehner

Figure 5. VMAT2 $\mathrm{L} 0$ animals display normal circadian activity but a premature shortened latency to behavioral signs of sleep. $A$, VMAT2 L 0 mice at 4- 6 months of age display shorter latency to behavioral signs of sleep compared with WT controls. VMAT2 WT and L0 animals have similar latencies to behavioral signs of sleep at $12-15$ and 24 months of age. Results represent the time (in minutes) passed until the animal achieved 2 min of uninterrupted sleep \pm SEM for eight animals per genotype. ${ }^{*} p<0.05$. $\boldsymbol{B}-\boldsymbol{E}$, VMAT2 $\mathrm{L} 0$ animals display normal circadian activity levels at 2, 4-6, 12-15, and 18 months of age, compared with age-matched WT controls. 

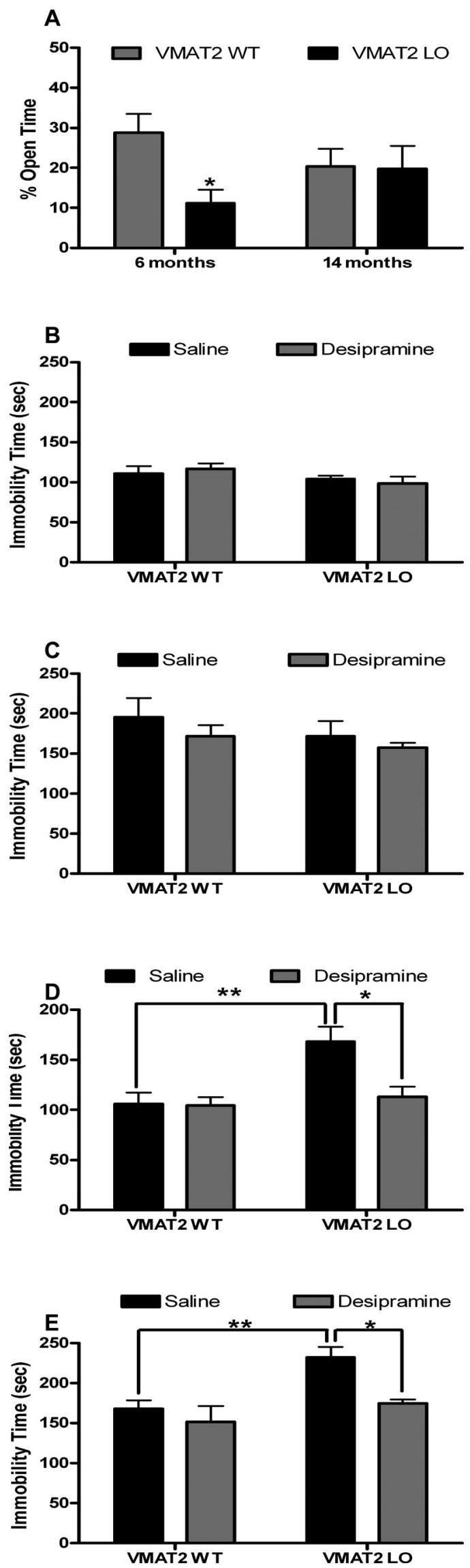

et al., 2001; Colebrooke et al., 2006; Caudle et al., 2007), which is accompanied by increased dopamine and serotonin turnover in multiple regions of the brain (Fig. 1) (Colebrooke et al., 2006; Caudle et al., 2007). Loss of VMAT2 function causes gradual neurodegeneration in the SNpc, LC, and DR of aged VMAT2deficient mice (T. N. Taylor and G. W. Miller, unpublished observations). In contrast, other pharmacological in vivo models of $\mathrm{PD}$, such as 6-OHDA lesions, cause sudden and profound loss of cell bodies. Although the precise mechanisms of cell death remain unclear, this progressive degeneration may be caused by oxidant species produced from improper monoamine storage within the neuron (Caudle et al., 2008). Catecholamines have the intrinsic ability to auto-oxidize, yielding reactive oxygen species and cysteinyl adducts; likewise, serotonin has an oxidizable indole ring (Graham, 1978; Jenner, 1998, 2003; Guillot and Miller, 2009). Presumably, improper storage of the monoamines contributes to progressive cellular injury.

Braak et al. (2002) and Langston (2006) have proposed that PD pathology actually begins in the lower brainstem and olfactory bulb, revealed by the presence of $\alpha$-synuclein-positive Lewy bodies. Olfaction abnormalities are present in $100 \%$ of PD patients, many noticing a decline in the sense of smell long before the onset of motor symptoms (Müller et al., 2002). Alterations in olfactory function are typically stable over time, nonresponsive to traditional PD therapeutics, and unrelated to disease stage or duration (Doty et al., 1992; Ziemssen and Reichmann, 2007), and have been suggested to be an excellent preclinical marker of PD. VMAT2-deficient mice demonstrate a progressive loss in olfactory discrimination beginning at 5 months of age, stabilizing at 6 months, and remaining unchanged at 12 months that appears to correlate to the loss of striatal DA transporter (Caudle et al., 2007), similar to that seen in patients (Siderowf et al., 2005; Ross et al., 2008).

Sleep disturbances have been shown to occur before the clinical presentation of motor deficits (Braak et al., 2003; Langston, 2006). Nocturnal sleep disruptions occur in $60-98 \%$ of PD patients, and are correlated with disease severity (Comella, 2003; Ziemssen and Reichmann, 2007). Sleep disturbances are manifested through a variety of syndromes including REM sleep behavioral disorder, excessive daytime sleepiness, sleep fragmentation, and deficiencies in sleep latency (Friedman, 1980; Comella, 2007; Ziemssen and Reichmann, 2007). VMAT2-deficient mice demonstrate a shorter latency to behavioral signs of sleep; however, more in-depth studies using EEGs must be performed to better understand the underlying sleep architecture in these mice.

$\leftarrow$

Figure 7. VMAT2 LO animals display an anxiety-like and a progressive depressive-like phenotype. $A$, Four to six-month-old VMAT2 $\mathrm{L} 0$ animals spend less time in the open arms and more time in the closed arms of the elevated plus maze compared with age-matched WT animals over the 5 min test period. At 12-15 months of age, VMAT2 WT and L0 animals display similar amounts of time in both the closed and open arms of the EPM. Results represent the mean time (in seconds) \pm SEM for seven mice per genotype. ${ }^{*} p<0.05$. B, C, Four- to six-month-old VMAT2 $\mathrm{L} 0$ animals have similar immobility times in the forced swim test $(\boldsymbol{B})$ and tail suspension test $(\boldsymbol{C})$ compared with age-matched WT animals; the immobility times of both genotypes is not affected by $100 \mu \mathrm{l}$ of $5 \mathrm{mg} / \mathrm{kg}$ desipramine 30 min before testing given intraperitoneally. $\boldsymbol{D}$, At 12-15 months of age, VMAT2 WT animals remain nonresponsive to desipramine administration. However, VMAT2 LO mice have an increased immobility time, which is decreased to WT levels when dosed intraperitoneally with $100 \mu \mathrm{lof} 5 \mathrm{mg} / \mathrm{kg}$ desipramine 30 min before testing. Results represent the mean time (in seconds) \pm SEM for four to five mice per genotype. ${ }^{*} p<$ $0.05 ;{ }^{* *} p<0.01 . E$, At $12-15$ months of age, VMAT2 LO mice display a significant increase in immobility time compared with WT control animals, which is ameliorated by $5 \mathrm{mg} / \mathrm{kg}$ desipramine. ${ }^{* *} p<0.01, n=4-5$ mice per genotype. 
A

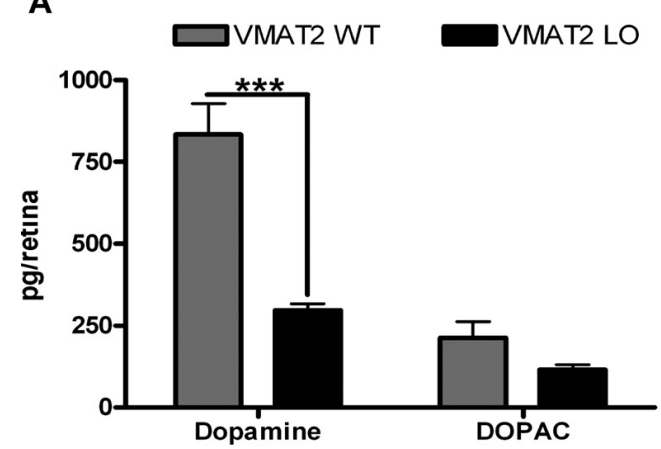

B
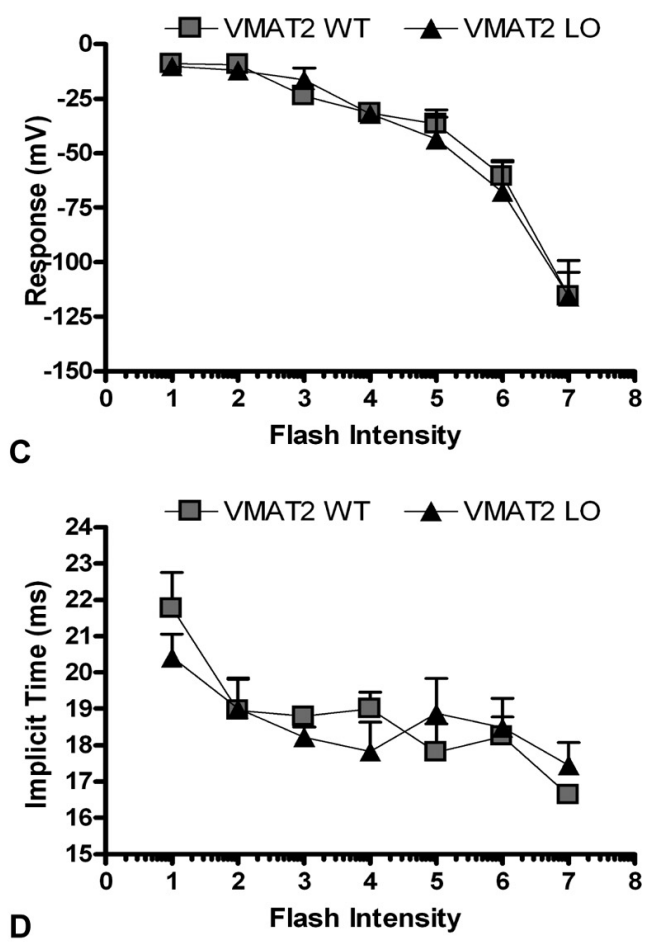

D

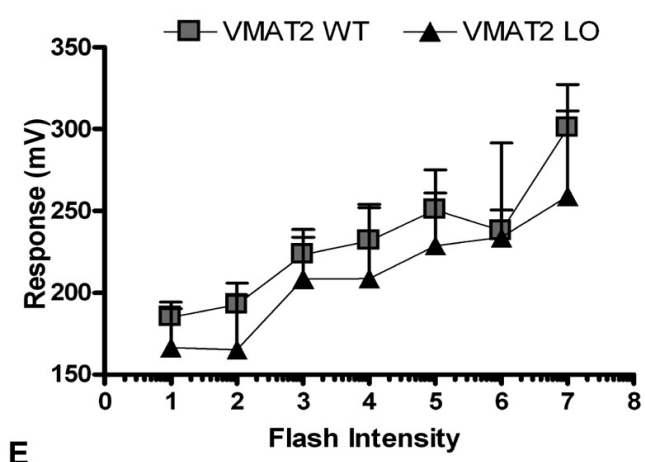

E

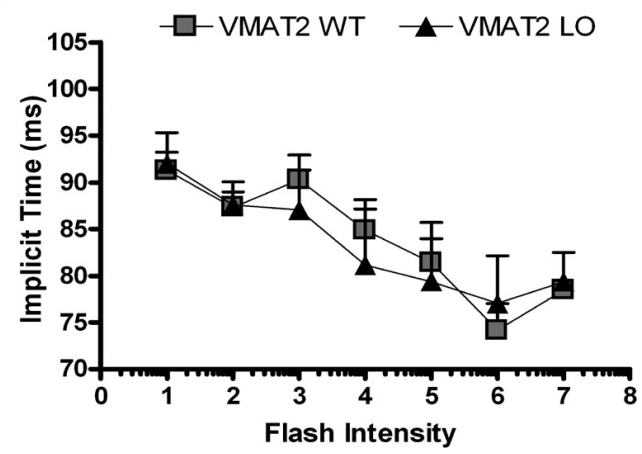

Gastrointestinal dysfunction is certainly one of the most common and possibly one of the earliest symptoms of PD (Edwards et al., 1993; Abbott et al., 2001; Pfeiffer, 2003). Dopamine depletion in the colon and Lewy bodies throughout the enteric nervous system suggest that GI symptoms are a manifestation of the primary disease process, rather than an epiphenomenon related to motor dysfunction (Qualman et al., 1984; Kupsky et al., 1987; Wakabayashi et al., 1988; Edwards et al., 1993; Singaram et al., 1995; Abbott et al., 2001; Langston, 2006). Unfortunately, treatment of PD with L-DOPA may exacerbate GI dysfunction by slowing gastrointestinal motility, even though increased colonic transport time may derive from the same processes that cause motor abnormalities (Abbott et al., 2001; Ziemssen and Reichmann, 2007). The VMAT2-deficient mice exhibit some disturbances in GI dysfunction, including delayed gastric emptying and altered stool frequency that declines with age (Fig. 6), indicating that reduced vesicular monoamine storage impacts GI function.

Disruptions in DA, NE, and 5-HT neurotransmission have been found in PD patients with anxiety and/or depression, including degeneration of the LC and DR (Lemke et al., 2004; Remy et al., 2005; Ziemssen and Reichmann, 2007). Depression in PD has been difficult to study since it differs from major depression alone; only $\sim 6 \%$ of PD patients suffer from major depression (Tandberg et al., 1996; Ziemssen and Reichmann, 2007). Moreover, a reliable rating scale does not currently exist to measure depressive symptoms in PD patients (Tandberg et al., 1996; Ziemssen and Reichmann, 2007). However, antidepressants such as nortriptyline and paroxetine have proven effective in depressed PD patients without worsening motor symptoms (Andersen et al., 1980; Ceravolo et al., 2000). The role of VMAT2 in anxiety and depression was discovered decades ago and is well characterized; reserpine, a VMAT2 inhibitor, has been shown to precipitate depressive-like symptoms in humans (Freis, 1954). Recently, Fukui et al. (2007) have shown that mice with a 50\% reduction in VMAT2 display depressive behavior in the forced swim and tail suspension test that is ameliorated by acute antidepressant therapy. However, these VMAT2 heterozygous knock-outs do not display anxiety-like behavior (Fukui et al., 2007). We found that the severe reduction of VMAT2 expression in the VMAT2deficient mice does trigger both anxiety and progressive depressive behavior. VMAT2-deficient mice showed a significant increase in percentage open arm time in the elevated plus maze at 4-6 months of age, while the increased immobility time in the forced swim and tail suspension tests did not occur until 12 months of age, suggesting that anxiety precedes depressive symptoms in VMAT2-deficient animals. Additionally, a low dose of desipramine that had no effect in wild-type animals was able to normalize immobility times in VMAT2-deficient mice. It is also important to note that many of the behaviors that are normal in PD patients (sensory, vision, strength) are also normal in the VMAT2-deficient mice, demonstrating a selective deficit in monoamine-related behaviors.

Data from the VMAT2-deficient mice suggest that all monoamine transmitter systems, not just DA, play a role in the clinical manifestations of PD. Classical descriptions/hypotheses about

$\leftarrow$

Figure 8. VMAT2 $L 0$ mice have decreased retinal DA but normal vision. $A$, VMAT2 $L$ animals have a $64 \%$ decrease in retinal $D A$, concurrent $45 \%$ decrease in retinal DOPAC, and increased DA turnover. $\boldsymbol{B}-\boldsymbol{E}$, No changes were observed in A-wave amplitude $(\boldsymbol{B})$ and implicit time $(\boldsymbol{C})$ or in B-wave amplitude $(\boldsymbol{D})$ and implicit time $(\boldsymbol{E})$ in VMAT2 LO mice compared with age-matched VMAT2 WT mice. 
the pathogenesis of PD suggest that the degeneration or loss of DA neurons is the major contributor to the development of the disease. However, it is not implausible to couple NE and 5-HT with DA in these classically established hypotheses for PD genesis. NE and 5-HT share structural similarities with DA; NE shares a catechol ring, and all three species have the ability to oxidize within the cell, yielding deleterious effects (Guillot and Miller, 2009). Similarly, the qualities that predispose the nigrostriatal system to oxidative damage may not be unique (Ahlskog, 2007); rather, these factors may be present in all monoaminergic neurons to varying degrees. Although the cause of the nonmotor symptoms associated with PD remains unknown, it is clear that they are not caused purely by dopaminergic deficits; our data suggest that NE and 5-HT may contribute as well. When combined with the previously reported nigrostriatal degeneration in this model, the observed nonmotor symptoms suggest that the VMAT2-deficient mice represent an excellent model of the monoaminergic deficits that manifest in human PD.

\section{References}

Abbott RD, Petrovitch H, White LR, Masaki KH, Tanner CM, Curb JD, Grandinetti A, Blanchette PL, Popper JS, Ross GW (2001) Frequency of bowel movements and the future risk of Parkinson's disease. Neurology 57:456-462.

Ahlskog JE (2007) Beating a dead horse: dopamine and Parkinson disease. Neurology 69:1701-1711.

Andersen J, Aabro E, Gulmann N, Hjelmsted A, Pedersen HE (1980) Antidepressive treatment in Parkinson's disease. A controlled trial of the effect of nortriptyline in patients with Parkinson's disease treated with L-DOPA. Acta Neurol Scand 62:210-219.

Antelman SM, Caggiula AR (1977) Norepinephrine-dopamine interactions and behavior. Science 195:646-653.

Braak H, Del Tredici K, Bratzke H, Hamm-Clement J, Sandmann-Keil D, Rüb U (2002) Staging of the intracerebral inclusion body pathology associated with idiopathic Parkinson's disease (preclinical and clinical stages). J Neurol 249 [Suppl 3]:III/1-5.

Braak H, Del Tredici K, Rüb U, de Vos RA, Jansen Steur EN, Braak E (2003) Staging of brain pathology related to sporadic Parkinson's disease. Neurobiol Aging 24:197-211.

Caudle WM, Richardson JR, Delea KC, Guillot TS, Wang M, Pennell KD, Miller GW (2006) Polychlorinated biphenyl-induced reduction of dopamine transporter expression as a precursor to Parkinson's diseaseassociated dopamine toxicity. Toxicol Sci 92:490-499.

Caudle WM, Richardson JR, Wang MZ, Taylor TN, Guillot TS, McCormack AL, Colebrooke RE, Di Monte DA, Emson PC, Miller GW (2007) Reduced vesicular storage of dopamine causes progressive nigrostriatal neurodegeneration. J Neurosci 27:8138-8148.

Caudle WM, Colebrooke RE, Emson PC, Miller GW (2008) Altered vesicular dopamine storage in Parkinson's disease: a premature demise. Trends Neurosci 31:303-308.

Ceravolo R, Nuti A, Piccinni A, Dell'Agnello G, Bellini G, Gambaccini G, Dell'Osso L, Murri L, Bonuccelli U (2000) Paroxetine in Parkinson's disease: effects on motor and depressive symptoms. Neurology 55:1216-1218.

Colebrooke RE, Humby T, Lynch PJ, McGowan DP, Xia J, Emson PC (2006) Age-related decline in striatal dopamine content and motor performance occurs in the absence of nigral cell loss in a genetic mouse model of Parkinson's disease. Eur J Neurosci 24:2622-2630.

Comella CL (2003) Sleep disturbances in Parkinson's disease. Curr Neurol Neurosci Rep 3:173-180.

Comella CL (2007) Sleep disorders in Parkinson's disease: an overview. Mov Disord 22 [Suppl 17]:S367-S373.

Cryan JF, O'Leary OF, Jin SH, Friedland JC, Ouyang M, Hirsch BR, Page ME, Dalvi A, Thomas SA, Lucki I (2004) Norepinephrine-deficient mice lack responses to antidepressant drugs, including selective serotonin reuptake inhibitors. Proc Natl Acad Sci U S A 101:8186-8191.

Dauer W, Przedborski S (2003) Parkinson's disease: mechanisms and models. Neuron 39:889-909.

Doty RL, Stern MB, Pfeiffer C, Gollomp SM, Hurtig HI (1992) Bilateral olfactory dysfunction in early stage treated and untreated idiopathic Parkinson's disease. J Neurol Neurosurg Psychiatry 55:138-142.

Edwards L, Quigley EM, Hofman R, Pfeiffer RF (1993) Gastrointestinal symptoms in Parkinson disease: 18-month follow-up study. Mov Disord 8:83-86.

Fahn S, Sulzer D (2004) Neurodegeneration and neuroprotection in Parkinson disease. NeuroRx 1:139-154.

File SE, Baldwin HA, Johnston AL, Wilks LJ (1988) Behavioral effects of acute and chronic administration of caffeine in the rat. Pharmacol Biochem Behav 30:809-815.

Freis ED (1954) Mental depression in hypertensive patients treated for long periods with large doses of reserpine. N Engl J Med 251:1006-1008.

Friedman A (1980) Sleep pattern in Parkinson's disease. Acta Med Pol 21:193-199.

Fukui M, Rodriguiz RM, Zhou J, Jiang SX, Phillips LE, Caron MG, Wetsel WC (2007) Vmat2 heterozygous mutant mice display a depressive-like phenotype. J Neurosci 27:10520-10529.

Gesi M, Soldani P, Giorgi FS, Santinami A, Bonaccorsi I, Fornai F (2000) The role of the locus coeruleus in the development of Parkinson's disease. Neurosci Biobehav Rev 24:655-668.

Graham DG (1978) Oxidative pathways for catecholamines in the genesis of neuromelanin and cytotoxic quinones. Mol Pharmacol 14:633-643.

Grill HJ, Norgren R (1978) The taste reactivity test. I. Mimetic responses to gustatory stimuli in neurologically normal rats. Brain Res 143:263-279.

Guillot TS, Miller GW (2009) Protective actions of the vesicular monoamine transporter 2 (VMAT2) in monoaminergic neurons. Mol Neurobiol 39:149-170.

Halliday GM, Blumbergs PC, Cotton RG, Blessing WW, Geffen LB (1990) Loss of brainstem serotonin- and substance P-containing neurons in Parkinson's disease. Brain Res 510:104-107.

Jackson CR, Chaurasia SS, Zhou H, Haque R, Storm DR, Iuvone PM (2009) Essential roles of dopamine D4 receptors and the type 1 adenylyl cyclase in photic control of cyclic AMP in photoreceptor cells. J Neurochem 109:148-157.

Jellinger KA (1991) Pathology of Parkinson's disease. Changes other than the nigrostriatal pathway. Mol Chem Neuropathol 14:153-197.

Jenner P (1998) Oxidative mechanisms in nigral cell death in Parkinson's disease. Mov Disord 13 [Suppl 1]:24-34.

Jenner P (2003) Oxidative stress in Parkinson's disease. Ann Neurol 53 [Suppl 3]:S26-S36; discussion S36-S28.

Jenner P, Olanow CW (2006) The pathogenesis of cell death in Parkinson's disease. Neurology 66:S24-36.

Kupsky WJ, Grimes MM, Sweeting J, Bertsch R, Cote LJ (1987) Parkinson's disease and megacolon: concentric hyaline inclusions (Lewy bodies) in enteric ganglion cells. Neurology 37:1253-1255.

Langston JW (2006) The Parkinson's complex: parkinsonism is just the tip of the iceberg. Ann Neurol 59:591-596.

Lemke MR, Fuchs G, Gemende I, Herting B, Oehlwein C, Reichmann H, Rieke J, Volkmann J (2004) Depression and Parkinson's disease. J Neurol 251 [Suppl 6]:VI/24-27.

Li ZS, Schmauss C, Cuenca A, Ratcliffe E, Gershon MD (2006) Physiological modulation of intestinal motility by enteric dopaminergic neurons and the $\mathrm{D}_{2}$ receptor: analysis of dopamine receptor expression, location, development, and function in wild-type and knock-out mice. J Neurosci 26:2798-2807.

Marien MR, Colpaert FC, Rosenquist AC (2004) Noradrenergic mechanisms in neurodegenerative diseases: a theory. Brain Res Brain Res Rev 45:38-78.

Mitchell HA, Bogenpohl JW, Liles LC, Epstein MP, Bozyczko-Coyne D, Williams M, Weinshenker D (2008) Behavioral responses of dopamine beta-hydroxylase knockout mice to modafinil suggest a dual noradrenergic-dopaminergic mechanism of action. Pharmacol Biochem Behav 91:217-222.

Mooslehner KA, Chan PM, Xu W, Liu L, Smadja C, Humby T, Allen ND, Wilkinson LS, Emson PC (2001) Mice with very low expression of the vesicular monoamine transporter 2 gene survive into adulthood: potential mouse model for parkinsonism. Mol Cell Biol 21:5321-5331.

Müller A, Reichmann H, Livermore A, Hummel T (2002) Olfactory function in idiopathic Parkinson's disease (IPD): results from cross-sectional studies in IPD patients and long-term follow-up of de-novo IPD patients. J Neural Transm 109:805-811.

Murai T, Müller U, Werheid K, Sorger D, Reuter M, Becker T, von Cramon 
DY, Barthel H (2001) In vivo evidence for differential association of striatal dopamine and midbrain serotonin systems with neuropsychiatric symptoms in Parkinson's disease. J Neuropsychiatry Clin Neurosci 13:222-228.

Olanow CW, Tatton WG (1999) Etiology and pathogenesis of Parkinson's disease. Annu Rev Neurosci 22:123-144.

Paine TA, Jackman SL, Olmstead MC (2002) Cocaine-induced anxiety: alleviation by diazepam, but not buspirone, dimenhydrinate or diphenhydramine. Behav Pharmacol 13:511-523.

Parkinson J (1817) An essay on the shaking palsy. London: Sherwood, Neely, Jones.

Patel J, Mooslehner KA, Chan PM, Emson PC, Stamford JA (2003) Presynaptic control of striatal dopamine neurotransmission in adult vesicular monoamine transporter 2 (VMAT2) mutant mice. J Neurochem 85:898-910.

Pellow S, Chopin P, File SE, Briley M (1985) Validation of open:closed arm entries in an elevated plus-maze as a measure of anxiety in the rat. J Neurosci Methods 14:149-167.

Pfeiffer RF (2003) Gastrointestinal dysfunction in Parkinson's disease. Lancet Neurol 2:107-116.

Porsolt RD, Bertin A, Blavet N, Deniel M, Jalfre M (1979) Immobility induced by forced swimming in rats: effects of agents which modify central catecholamine and serotonin activity. Eur J Pharmacol 57:201-210.

Qualman SJ, Haupt HM, Yang P, Hamilton SR (1984) Esophageal Lewy bodies associated with ganglion cell loss in achalasia. Similarity to Parkinson's disease. Gastroenterology 87:848-856.

Remy P, Doder M, Lees A, Turjanski N, Brooks D (2005) Depression in Parkinson's disease: loss of dopamine and noradrenaline innervation in the limbic system. Brain 128:1314-1322.

Richardson JR, Miller GW (2004) Acute exposure to aroclor 1016 or 1260 differentially affects dopamine transporter and vesicular monoamine transporter 2 levels. Toxicol Lett 148:29-40.

Rommelfanger KS, Weinshenker D (2007) Norepinephrine: The redheaded stepchild of Parkinson's disease. Biochem Pharmacol 74:177-190.

Ross GW, Petrovitch H, Abbott RD, Tanner CM, Popper J, Masaki K, Launer L, White LR (2008) Association of olfactory dysfunction with risk for future Parkinson's disease. Ann Neurol 63:167-173.

Schallert T, Whishaw IQ (1978) Two types of aphagia and two types of sensorimotor impairment after lateral hypothalamic lesions: observations in normal weight, dieted, and fattened rats. J Comp Physiol Psychol 92:720-741.
Schallert T, Fleming SM, Leasure JL, Tillerson JL, Bland ST (2000) CNS plasticity and assessment of forelimb sensorimotor outcome in unilateral rat models of stroke, cortical ablation, parkinsonism and spinal cord injury. Neuropharmacology 39:777-787.

Schank JR, Liles LC, Weinshenker D (2008) Norepinephrine signaling through beta-adrenergic receptors is critical for expression of cocaineinduced anxiety. Biol Psychiatry 63:1007-1012.

Siderowf A, Newberg A, Chou KL, Lloyd M, Colcher A, Hurtig HI, Stern MB, Doty RL, Mozley PD, Wintering N, Duda JE, Weintraub D, Moberg PJ (2005) [99mTc]TRODAT-1 SPECT imaging correlates with odor identification in early Parkinson disease. Neurology 64:1716-1720.

Singaram C, Ashraf W, Gaumnitz EA, Torbey C, Sengupta A, Pfeiffer R, Quigley EM (1995) Dopaminergic defect of enteric nervous system in Parkinson's disease patients with chronic constipation. Lancet 346:861-864.

Specht CG, Schoepfer R (2001) Deletion of the alpha-synuclein locus in a subpopulation of C57BL/6J inbred mice. BMC Neurosci 2:11.

Tandberg E, Larsen JP, Aarsland D, Cummings JL (1996) The occurrence of depression in Parkinson's disease. A community-based study. Arch Neurol 53:175-179.

Tillerson JL, Miller GW (2003) Grid performance test to measure behavioral impairment in the MPTP-treated-mouse model of parkinsonism. J Neurosci Methods 123:189-200.

Tillerson JL, Caudle WM, Parent JM, Gong C, Schallert T, Miller GW (2006) Olfactory discrimination deficits in mice lacking the dopamine transporter or the D2 dopamine receptor. Behav Brain Res 172:97-105.

Wakabayashi K, Takahashi H, Takeda S, Ohama E, Ikuta F (1988) Parkinson's disease: the presence of Lewy bodies in Auerbach's and Meissner's plexuses. Acta Neuropathol 76:217-221.

Whited KL, Thao D, Lloyd KC, Kopin AS, Raybould HE (2006) Targeted disruption of the murine CCK1 receptor gene reduces intestinal lipidinduced feedback inhibition of gastric function. Am J Physiol Gastrointest Liver Physiol 291:G156-162.

Xu F, Gainetdinov RR, Wetsel WC, Jones SR, Bohn LM, Miller GW, Wang YM, Caron MG (2000) Mice lacking the norepinephrine transporter are supersensitive to psychostimulants. Nat Neurosci 3:465-471.

Ziemssen T, Reichmann H (2007) Non-motor dysfunction in Parkinson's disease. Parkinsonism Relat Disord 13:323-332.

Zimmerman M, Chelminski I, McDermut W (2002) Major depressive disorder and axis I diagnostic comorbidity. J Clin Psychiatry 63:187-193. 